\section{Bioética da proteção e papel do Estado: problemas morais no acesso desigual à água potável}

\author{
The bioethics of protection and the state's \\ role: moral problems in unequal access \\ to drinking water
}

Carlos Antonio Alves Pontes 1

Fermin Roland Schramm 2
${ }^{1}$ Departamento de Saúde Coletiva, Centro de Pesquisas Aggeu Magalhães, Fundação Oswaldo Cruz, Recife, Brasil.

2 Departamento de Ciências Sociais, Escola Nacional de Saúde Pública Fundação Oswaldo Cruz, Rio de Janeiro, Brasil.

Correspondência C. A. A. Pontes

Departamento de Saúde Coletiva, Centro de Pesquisas Aggeu Magalhães, Fundação Oswaldo Cruz. Av. Moraes Rego s/n, C. P. 7472, Recife, $P E$ 50670-420, Brasil. cpontes@cpqam.fiocruz.br

\section{Abstract}

The aim of this study is to examine unequal access to drinking water as a public health problem in terms of normative and analytical tools in the bioethics of protection. Therefore, we analyze both the moral implications of unequal treatment of primary needs, such as situations of vulnerability and threat to population groups, and the public sector's responsibility in supplying safe water. In addition, solutions are proposed for the protection of public health and the promotion of legitimate personal development projects. The bioethics of protection reaffirms the state's role in maintaining the drinking water supply and recommends avoiding a policy of privatization of this public good, meanwhile justifying public policies to correct situations of social injustice.

Drinking Water; Bioethics; Public Health

\section{Introdução}

Com o processo de urbanização acelerada a partir da segunda metade do século XX, a tal ponto que mais da metade da população mundial vive atualmente em aglomerações urbanas, técnicas foram sendo desenvolvidas de modo que é possível o fornecimento de água potável em grandes volumes para atender a milhões de habitantes que se concentram nas médias e grandes cidades espalhadas por todo o globo terrestre. No entanto, a água potável não está atualmente disponível para todas as pessoas, em muitas sociedades. De fato, os países do mundo desenvolvido conseguem atender, na maioria das vezes e de forma universal, às necessidades de suas populações, por meio de sistemas coletivos de distribuição, que caracterizam um acesso adequado à água potável para todos. Ao contrário, os demais países apresentam parcelas significativas de suas populações urbanas sem ter acesso ou com um acesso precário à água potável.

Os problemas decorrentes de tal situação se refletem na persistência de enfermidades que poderiam ser prevenidas, caso houvesse um suprimento adequado de água de boa qualidade, condição indispensável para uma qualidade de vida razoável. Com efeito, por ser um bem de primeira necessidade, a água é utilizada, cotidianamente, para o preparo de alimentos, matar a sede, higiene e asseio corporal, lim- 
peza de utensílios domésticos e da habitação, banho e descarga de vasos sanitários, dentre outros usos importantes, razão pela qual a condição existencial de não dispor de água potável em quantidade adequada compromete esses usos cotidianos, podendo expor as pessoas a riscos de adoecimento, como, também, limitar o desenvolvimento de legítimos projetos pessoais de vida. Essa questão fica evidente quando são colocados em tela as dificuldades enfrentadas por pessoas que não têm acesso à água potável, ou o acesso que tem é precário. "Você faz limpeza na casa só aos domingos: como a água só cai no sábado, você tem que aproveitar ou, então, ficar limpando na madrugada de sábado. Enquanto a água está caindo, você tá lavando roupa, areando as panelas ou fazendo faxina na madrugada. Isso tudo para economizar água, porque, até as seis horas da manhã de domingo, a água tá caindo e, quando parar, a caixa vai estar cheia para a semana toda. Querendo ou não, você tem que trabalhar de madrugada (Moradora do Complexo de Favelas Penha/Parque Proletário da Penha)" 1 (p. 67). O tempo gasto na espera por água é o tempo subtraído para a obtenção de outros bens essenciais, pois as pessoas que perdem tempo procurando um balde de água, todos os dias, deixam de fazer outras coisas importantes para o seu desenvolvimento pessoal. Um outro exemplo emblemático é o da cidade-piloto do Programa Fome Zero do Governo Federal, que pode ser lido em matéria de 1o de fevereiro de 2003 da Folha de S. Paulo. Os moradores de Guaribas consideram que a falta de água é problema mais grave: "a função de pegar água para o consumo da casa é das mulheres. Luciene da Silva Nascimento, 20, vai cinco vezes por dia à fonte de água que fica no alto de uma serra, um percurso de cerca de $2 \mathrm{~km}$ de barro e pedras. 'Criancinha de três anos já começa a carregar um baldinho para ir aprendendo', diz Luciene, mãe de uma menina de 11 meses. É na mesma fonte que mulheres e crianças aproveitam para lavar roupa e tomar banho. A primeira ida à fonte é ainda de madrugada, para ter água pela manhã. Na volta, elas descem o morro com o balde cheio de água na cabeça em passos rápidos, quase correndo, para não perder o equilíbrio" 2 (p. 8).

Sendo um bem essencial, indispensável à vida, a água deve, em princípio, ser servida a cada pessoa indistintamente, a menos que se detectem boas razões, eticamente sustentáveis, para agir de outro modo. O que se observa, no entanto, é que a apropriação da água é feita de forma diferenciada de uma sociedade para outra, como também entre os membros de uma mesma sociedade, sem que isso seja acompanhado de uma precisa e coerente razão moral. Por isso, desigualdades na distribuição da água potável podem se constituir em situações de injustiça, que vão refletir negativamente na qualidade de vida de pessoas e populações humanas. Portanto, são questões de conteúdo moral que devem ser examinadas à luz da ética aplicada, especialmente da bioética, preocupada com a qualidade da vida resultante das práticas humanas, que envolvem conflitos de interesses e valores entre atores sociais.

O objetivo deste artigo é examinar o acesso desigual à água potável como problemática de saúde pública, identificando e analisando as implicações morais do atendimento desigual de necessidades primárias, as situações de fragilidade e ameaça de grupos populacionais e as responsabilidades públicas para com o abastecimento de água; e propondo soluções, em bases racionais, para a construção de uma sociedade justa e equânime, comprometida com a proteção da saúde de seus membros, bem como com a promoção de seus legítimos projetos de desenvolvimento pessoal. Para tanto, é utilizada a bioética da proteção como uma teoria moral apropriada para a abordagem desses problemas, pertinentes ao campo da bioética social. Com efeito, é do ponto de vista da bioética da proteção que nos é possível reafirmar qual deve ser o papel de um Estado que se pretenda legítimo, garantindo o acesso universal à água potável, isto é, colocando em foco sua responsabilidade pela prestação dos serviços de saneamento, e, em particular, de abastecimento de água de boa qualidade. A partir de uma visão do acesso à água como direito, se desaconselham políticas de privatização em favor de políticas públicas que visem a correção de situações de injustiça social, protejam a saúde das populações e, em especial, dos grupos populacionais constantemente ameaçados, promovendo condições para uma melhor qualidade de vida.

\section{Bioética: definições e campo de aplicação}

A concepção de bioética aqui utilizada é aquela proposta por Kottow 3 (p. 53), que considera a bioética como "o conjunto de conceitos, argumentos e normas que valorizam e legitimam eticamente os atos humanos, que podem ter efeitos irreversíveis sobre fenômenos vitais".

Adotamos tal definição por considerá-la suficientemente abrangente para poder dar conta do vastíssimo espectro de atuação humana sobre o mundo vivo ("Lebenswelt") e que pode 
afetar positiva ou negativamente não só os seres humanos, mas qualquer outro ser vivo, como também os delicados equilíbrios autopoiéticos que caracterizam o meio ambiente. Além disso, e apesar de ser abrangente, esta concepção não é genérica demais, como aquela que define a bioética como sendo a "ética da vida", o que acaba tornando a ferramenta bioética praticamente inutilizável por aplicar-se praticamente a qualquer tipo de atividade humana. Em suma, a definição aqui adotada é bastante precisa sem ser reducionista, pois, como aponta Schramm, esta concepção de bioética permite que seja colocada em foco a característica pertinente da vida que merece, prima facie, proteção, isto é, a potencial irreversibilidade das ações humanas sobre os sistemas vivos, os quais dão sustentação à vida, inclusive humana, por meio dos equilíbrios bioecológicos 4 .

No entanto, a bioética não é apenas uma reflexão de segunda ordem, como qualquer outra ética, sobre os atos humanos, mas é, ainda, uma ética prática, ou aplicada, visto que pretende dirimir concretamente os conflitos morais 4 , ou seja, ela é ao mesmo tempo descritiva dos fatos consistentes em conflitos e dilemas morais existentes, e normativa, pois pretende prescrever e proscrever comportamentos, a partir de processos de crítica e justificação. Schramm ainda propõe que seja considerada uma terceira tarefa da bioética, que considera como sendo a mais abrangente e primária: a tarefa protetora. Com efeito, segundo o autor, essa dimensão corresponderia ao sentido mais arcaico veiculado pelo termo grego ethos, qual seja o de "guarida" para proteger os animais das intempéries e predadores e, por extensão, para a "proteção" dos humanos contra ameaças externas 4 .

Em se tratando de problemas que envolvem a privação ou o acesso precário à água potável, e portanto, relacionados à saúde pública, é importante notar que o que está em foco são interações entre instituições, coletividades e ambientes. Em conseqüência, faz-se necessário definir quais as ferramentas conceituais que serão utilizadas para a abordagem desses problemas, lembrando que o modelo principialista, baseado nos quatro princípios de "não-maleficência", "beneficência”, "autonomia” e "justiça”, mostra-se inadequado quando se tenta aplicá-lo diretamente na abordagem de problemas que ocorrem em contextos coletivos, como é o caso da saúde pública 5 e, a fortiori, ao âmbito da saúde global.

\section{Bioética da proteção}

Schramm \& Kottow 5 , reconhecendo que a bioética pouco se deteve nesse assunto, propõem a utilização do "princípio de proteção", entendido como uma especificação do princípio de responsabilidade, como o mais adequado para abordar os problemas morais relacionados com a saúde pública. Com base nesse princípio, definem uma bioética da proteção como sendo uma ética da responsabilidade social, em que deve se basear o Estado para assumir suas obrigações sanitárias para com as populações humanas consideradas em seus contextos reais, que são, ao mesmo tempo, naturais, culturais, sociais e ecoambientais. Lembram, inclusive, que a utilização que ora é feita do princípio de proteção é um resgate do papel protetor do Estado, considerado como fundamento moral da atuação do Estado Mínimo e que dá sustentáculo à legitimidade do Estado de bemestar contemporâneo. Com efeito, a partir do século XVIII, o Estado exerceu, e consolidou, o papel de resguardar interesses individuais, como o direito de propriedade e a integridade dos cidadãos, definindo, portanto, um primeiro nível de proteção referido aos indivíduos ou, melhor dito, a cada indivíduo, determinando, desta forma, o campo dos direitos humanos fundamentais da pessoa, chamados também direitos liberais. A saúde pública, que surge como assunto do Estado nesse mesmo período, exerceu também um papel protetor, controlando epidemias e influindo decisivamente na reforma sanitária dos ambientes urbanos e de trabalho 5, introduzindo, assim, um segundo nível de proteção, referente não mais a indivíduos, mas sim, a populações, determinando, portanto, o campo dos direitos sociais.

Os autores procuram mostrar que o princípio de proteção atende aos requisitos de uma ética em saúde pública e permite a justificação e a análise moral de políticas públicas, ao requerer a clara identificação dos objetivos e dos atores envolvidos em sua implementação, assim como a especificação dos meios adequados de sua execução.

Por outro lado, para os autores, o princípio da proteção seria uma atualização e uma contextualização do princípio da responsabilidade, uma vez que se aplica a um agir como resposta a situações de fragilização ou ameaça de seres humanos. Os autores, examinando duas concepções, que admitem como sendo prima facie aplicáveis à saúde pública - a responsabilidade ôntica (relativa ao "ser"), de Hans Jonas, e a responsabilidade diacônica (relativa ao "tu" ou “outro"), de Emanuel Lévinas - mostram que 
tais concepções não são de fato aplicáveis à saúde pública, seja porque a categoria de "ser" é uma categoria metafísica, que não permite identificar claramente que tipo de "ser" deveria ser objeto de proteção, seja porque a responsabilidade incondicional, implicada pela visão de Lévinas, talvez aplicável a pequenas comunidades orgânicas, parece ser demasiadamente forte quando aplicadas a coletividades maiores, formadas por diferentes tipos de comunidades com valores diferentes, como é o caso das sociedades seculares e pluralistas contemporâneas. Concluem, assim, que o princípio de proteção ultrapassaria essas duas concepções da responsabilidade, permitindo uma melhor aplicabilidade. No entanto, o denominador comum que resulta da comparação entre essas três concepções reside, fundamentalmente, na característica de serem compromissos assumidos livremente, ou seja, de se posicionarem para responder voluntariamente às necessidades dos outros. Assim, um agente moral, assumindo livremente seu ato, será sempre responsável por suas decisões e pelas decorrentes conseqüências 5, o que, em última análise, corresponde a alguma forma de proteção do "outro", que pode ser o "outro" humano ou "outro" ser vivo. Com efeito, se tomarmos a concepção da responsabilidade ôntica de Jonas, esta pode ser exemplificada pela situação arquetípica de proteção dos pais frente ao recém-nascido. Mas, se equipararmos esse tipo de responsabilidade com aquela de um gestor público corre-se, inevitavelmente, o risco de paternalismo, atualmente bastante estigmatizado tanto pelas sociedades pluralistas e complexas como pela própria bioética laica. Ademais, no nível de interação entre instituições e coletividades, a atribuição desse tipo de responsabilidade seria pouco operacional, uma vez que o agente moral seria de difícil identificação. De fato, a concepção de Jonas implica justamente que o "ser" não seja reduzido a ente, isto é, objetivável como algo passível de ser determinado e localizado, devendo, portanto, permanecer um "ser" sui generis 5 . Mas isso faz com que o destinatário da responsabilidade ôntica se torne um objeto praticamente vazio. No que diz respeito à concepção de responsabilidade diacônica de Lévinas, é o conceito de responsabilidade para com o "outro" que os dois autores consideram forte demais. Com efeito, Lévinas dá como exemplo o caso do "outro" desamparado que me incita a assumir uma responsabilidade incondicional, o que nos leva a uma espécie de solidariedade em que o "eu" se subordina totalmente ao "outro", em princípio até desaparecer. Dessa forma, o "eu" desaparece, confundido-se com o “outro", ou sendo subsumido por este, o que é pelo menos implausível fora de uma relação "forte" como, por exemplo, a amorosa. Assim sendo, torna-se difícil conceber como se poderia aplicar tal conceito de responsabilidade no âmbito das políticas públicas, quando a responsabilidade incondicional deixa o agente moral em situação assimétrica de subordinação e não de reciprocidade, tendo de tomar decisões que só dependem de sua percepção das necessidades do "outro", o que parece muito problemático numa sociedade de consumidores e de pesquisas de opinião, como são as sociedades atuais 5 .

O princípio de proteção pretende justamente evitar essas dificuldades, que, para tanto, deveria apresentar determinadas características. A primeira delas seria a "gratuidade" no sentido do Estado (ou qualquer outra instância que tenha um papel similar) oferecer espontaneamente a proteção como um serviço gratuito, sem que isso seja, cada vez, requerido pelos sujeitos a serem protegidos, sendo que esses podem ou não aceitar tal serviço (neste sentido recupera-se não somente a mensagem da responsabilidade diacônica, mas também prima facie, o respeito à autonomia, evitando o paternalismo). A segunda seria a "vinculação", no sentido de que, uma vez livremente assumida pelos sujeitos e as populações a serem protegidas, a proteção se converteria, para a instância protetora, em um compromisso irrenunciável (também previsto pela responsabilidade diacônica). Por fim, a terceira seria a "cobertura" efetiva das necessidades do afetado que merecem legitimamente proteção 5 . Sendo que o termo "legitimamente" indica aqui uma delimitação da responsabilidade diacônica que não pode mais ser considerada "incondicional".

Assim, a proteção pode ser entendida como o resguardo ou cobertura de necessidades essenciais, ou seja, a proteção deve garantir que requerimentos moralmente legítimos sejam atendidos, de modo que toda pessoa necessitada possa estar em condições de conseguir outros bens, ou satisfazer outros interesses contidos em seus projetos de vida e que dependem da satisfação das necessidades básicas ou essenciais. Embora seja sempre difícil estabelecer, de forma objetiva e rigorosa, que necessidades essenciais seriam essas - haverá sempre um componente sociocultural em sua formulação e longas discussões sobre o que pode ou não ser considerado como essencial - é possível reconhecer razoavelmente requerimentos plausíveis, que se diferenciam de caprichos ou desejos individuais, que não podem ser exigidos à comunidade. Por exemplo, necessidades, 
tais como saúde, educação, alimento, vestimenta, abastecimento de água, segurança e moradia, são consideradas como itens indispensáveis que devem ser garantidos para todas as pessoas, que sozinhas não poderiam obtê-los 6 .

Resumindo, o princípio de proteção, aplicado à saúde pública, exige que deva ser especificado, claramente, aquilo que deve ser protegido, quem deve proteger o quê e para quem a proteção está dirigida, tornando-se, portanto, operacional (contrariamente à responsabilidade ôntica e à responsabilidade diacônica que não permitem isso). Em particular, a população (ou os grupos populacionais a serem protegidos em suas necessidades específicas) deve ser esclarecida sobre as medidas protetoras, caso contrário, estas só poderão ser percebidas como paternalistas e/ou arbitrárias, tornandoas, portanto, ineficazes. Tais grupos podem ser identificados, por exemplo, com o auxílio da epidemiologia, por tratar-se, reconhecidamente, da disciplina da saúde pública especializada no estudo das ocorrências e distribuição das formas mórbidas nas populações, sendo, portanto, um indispensável auxílio para a instância protetora determinar tanto o objeto como os sujeitos da proteção. É nesse sentido que muitos estudos, de base epidemiológica, vêm sendo empreendidos no sentido de melhor compreender as relações entre saúde e saneamento, de forma que seja possível a mensuração dos impactos na saúde, tanto para a identificação de condições inadequadas de saneamento, quanto para a avaliação das ações de saneamento necessárias para alcançar situações de salubridade ambiental 7,8,9,10,11. Outras disciplinas podem também ser úteis, desde que proporcionem conhecimentos no sentido de revelar desigualdades e condições iníquas de vida, que necessitam de intervenção do poder público para tentar equacioná-las. Tais aportes podem vir, por exemplo, da sociologia, da geografia crítica, das ciências políticas e outras ciências que se preocupam em trabalhar os contextos de desenvolvimento humano. Assim sendo, todas essas disciplinas podem ser consideradas aliadas da ética aplicada na medida em que ajudam a construir, cada uma com base em seu ponto de vista disciplinar, o quadro sanitário pertinente, sobre o qual deverá verter a análise bioética dos atos legítimos e considerados necessários para proteger indivíduos e populações necessitados.

\section{Papel do Estado quanto ao acesso à água potável}

Como questão de saúde pública, o problema do acesso à água pode ser abordado do ponto de vista da bioética de proteção, perguntando, por exemplo: deve o Estado assumir um papel protetor no que se refere à água potável? Quais medidas devem ser essas para legitimar esse papel?

Historicamente, os ambientes urbanos se estruturaram pari passu com a evolução das técnicas de obtenção de água, de tal sorte que é somente com a introdução das bombas hidráulicas, acionadas por máquina a vapor e a utilização de tubulações de ferro fundido, que foi possível atender aos grandes contingentes populacionais que acorriam às cidades em formação, por impulso da revolução industrial, exigente em mão-de-obra como força de trabalho para a produção dos bens econômicos. Inicialmente captada diretamente de rios poluídos e distribuída sem tratamento, a água se tornou um veículo de doenças numa escala inédita na história da humanidade. Com efeito, as pandemias de cólera no século XIX só ocorreram devido ao fato dos sistemas de abastecimento de água funcionarem como uma espécie de ciclo fechado. As recém-inventadas bombas hidráulicas captavam a água contaminada pelas fezes dos doentes de cólera, e a distribuía para o consumo de cidades inteiras.

A intervenção do Estado foi decisiva para a superação desse problema, realizando ações protetoras à medida que o conhecimento ia desvelando as relações causais entre qualidade da água e doença, e a tecnologia ia produzindo formas cada vez mais sofisticadas de obter água e transformá-la, para atender critérios de qualidade e, assim, garantir que não se tornasse danosa para a saúde humana.

O papel protetor do Estado foi além da questão do fornecimento de água potável, e também se fez notar no disciplinamento dos espaços públicos, quer seja para o uso e ocupação do solo, quer seja definindo critérios de qualidade das obras com vista à preservação de condições de salubridade.

Nos ambientes urbanos, a obtenção de água potável é, necessariamente, dependente de soluções coletivas. Como tais, constituem, certamente, uma questão pertinente de saúde pública. As medidas que legitimam o papel do Estado como protetor da saúde pública, no que se refere à água potável, devem ser aquelas que proporcionem a todo cidadão dispor de água em quantidade suficiente e qualidade adequada para atender a suas necessidades básicas. 
Tais medidas são justificadas por ser a água um bem primário. Daí se infere que é razoável admitir que o Estado deva prover esse bem.

Há três formas de fazer isso: (a) provisionando diretamente por meio de instituições públicas de direito público; (b) provisionando diretamente por meio de instituições públicas de direito privado; e (c) provisionando indiretamente por meio de instituições privadas. Nas duas primeiras opções, o Estado é o responsável direto pela prestação do serviço, e deve desenvolver ações adequadas para que seu papel de protetor seja legítimo, o que significa dispor de órgãos especializados, tanto para a execução técnico-operacional do processo de captar, tratar e distribuir a água, quanto para a fiscalização e controle da qualidade. Na terceira opção, o Estado transfere as funções executoras para as instituições privadas e mantém suas funções de fiscalização e controle de qualidade. O Estado, nesse caso, deve exercer um papel de regulador da relação entre o ente privado, prestador do serviço, e o usuário do mesmo.

Dessa forma, configuram-se duas situações: uma em que o Estado é diretamente responsável pela prestação dos serviços de abastecimento de água, preservando a gestão pública dos organismos executores; outra em que o Estado transfere a responsabilidade para entes privados, e os serviços de abastecimento de água passam a ter uma gestão privada. Cabe aqui uma pergunta: estaria o papel protetor do Estado comprometido quando é privada a gestão de serviços de abastecimento de água?

Na primeira situação, as relações são de caráter público, portanto o usuário da água preserva sua condição de cidadania frente às instituições públicas responsáveis pelo serviço, que devem garantir o acesso universal à água potável, em atendimento aos requisitos de justiça sanitária e do princípio de proteção. Já na situação em que os serviços sejam prestados por entes privados, a água passa a ser uma simples mercadoria, e os direitos de cidadania seriam exercidos pelos usuários na qualidade de consumidores. As relações teriam, dessa forma, caráter privado, e as instituições públicas só poderiam, em princípio, agir no sentido de evitar abusos, como, por exemplo, o estabelecimento de preços exorbitantes, e não poderiam exigir, em princípio, o atendimento universal; ou seja, não poderiam exigir que a empresa privada, que opera mediante lucro, atendesse a quem não pudesse pagar. Mas, nesse caso, estariam comprometidos tanto o requisito de justiça sanitária como o princípio de proteção que, como vimos, devem ser exercidos no sentido de cobrir as necessidades básicas para a construção de um ordenamento social justo e de proteger a qualidade de vida das populações.

Uma forma de superar essa dificuldade seria o Estado adotar uma política de complementação, destinando subsídios para entes privados fazerem frente a problemas de dificuldades de pagamento. Estaria assim resolvido o problema de garantir acesso universal à água potável?

Para responder essa pergunta, é necessário observar os contextos sócio-econômicos. Se considerarmos uma sociedade suficientemente desenvolvida e com condições mais igualitárias, podemos supor que a população, de uma forma geral, tenha condições de pagar pelos serviços privados e que sejam boas as condições de infra-estrutura instalada. Eventualmente haverá pessoas com dificuldades para arcar com despesas do serviço de água. Essas pessoas deveriam sofrer suspensão do seu fornecimento? Como deve agir o Estado em situações de suspensão de fornecimento por falta de pagamento do usuário-consumidor? Seria justo aceitar a situação de privação de um bem primário por alguém não ter como pagar? $\mathrm{O}$ Estado não poderia exigir obrigatoriedade do fornecimento de água sem pagamento, pois os custos e a perda de lucro penalizariam o ente privado. Caberia, então, algum tipo de compensação para o prestador de serviço privado, com recursos fiscais do próprio Estado. Supondo que a quantidade de pessoas em situação de não poder arcar com as despesas seja ínfima, é razoável admitir que este problema estaria sanado com uma intervenção compensatória do Estado. Mas considerando o contexto de uma sociedade de desigualdades mais acentuadas, as dificuldades para manter a condição de usuário-consumidor são muito maiores. É de se esperar que os problemas de dificuldade de pagamento persistam numa maior escala. Mecanismos de compensação pelo Estado deveriam, então, ser mais vigorosos e se dar em maiores proporções.

\section{Desigualdades no acesso à água potável}

Além de problemas com a capacidade de pagamento, há que se considerar os contingentes populacionais que sobrevivem à margem dos sistemas públicos, como é o caso de parte considerável não só da sociedade brasileira, mas de todo o mundo dito subdesenvolvido e em desenvolvimento. Embora os porcentuais de cobertura, em todas as regiões do mundo, já alcancem cifras elevadas, acima de 85,0\%, é significativa a diferença nos tipos de tecnologia em- 
pregados, que vão determinar a precariedade e má qualidade do acesso à água potável. Enquanto a América do Norte e a Europa apresentam como tecnologia empregada a ligação domiciliar à rede pública, para praticamente $100,0 \%$ da cobertura por abastecimento de água, África, Ásia e América Latina apresentam porcentuais bem menores. Na África, apenas $24,0 \%$ da cobertura por abastecimento de água é feita com ligações à rede pública. Na Ásia, esse percentual chega a 49,0\%, e na América Latina e Caribe o número de ligações à rede pública é de 47,0\% (http://www.who.int/water_sanitario_health/Globalassement/GlasspdfTOCspan.htm, acessado em Jul/2002).

Isso significa que metade das populações urbanas com atendimento na Ásia, América Latina, Caribe e três quartos na África, são abastecidos por meio de tecnologias que não podem ser consideradas adequadas para um fornecimento de água sanitariamente seguro. Os sistemas com distribuição de água por redes públicas são, normalmente, projetados e operados para fornecer água com teores de cloro residual de no mínimo 0,1mg/l - Portaria no 1.469 (Diário Oficial da União, 2000; $29 \mathrm{dez}$ ) estabelece $0,2 \mathrm{mg} / 1$ para qualquer ponto da rede de distribuição -, como forma de garantir a qualidade sanitária. No que se refere às outras formas de abastecimento, é bastante incomum a água receber algum tipo de tratamento para a sua desinfecção. Um outro aspecto, também importante, é a quantidade disponível. As populações que dispõem de ligações à rede pública, normalmente, conseguem obter água em maior quantidade, sem ter de se deslocar para buscar água em outro local (http://www.who. int/water_sanitario_health/Globalassement / GlasspdfTOCspan.htm, acessado em Jul/2002).

Embora, em princípio, os sistemas com distribuição pública sejam mais adequados para fornecer água sanitariamente segura, um em cada cinco sistemas nas regiões da África, Ásia, América Latina e Caribe não faz a desinfecção da água (http://www.who.int/water_sanitation_ health/Globalassessment/GlasspdfTOCspan.htm, acessado em Jul/2002). O Informe Regional da Organização Mundial da Saúde/Organização Pan-Americana da Saúde (OMS/OPAS) (http:// www.cepis.ops-oms.org, acessado em Jul/2002) estima que $59,0 \%$ da população da América Latina e Caribe recebem regularmente água desinfetada. Com o ressurgimento da cólera na região das Américas, a partir de 1991 - destaca o informe regional - a maioria dos países aumentou o monitoramento e controle da qualidade da água, particularmente no que se refere à desinfecção da água nos sistemas de distribuição.
Também foram introduzidas práticas para a desinfecção domiciliar da água, em lugares onde não havia sistemas coletivos de abastecimento, e quando havia, funcionavam em regime de intermitência. No entanto, muitos problemas ainda persistem, quer por descontinuidade do suprimento de cloro em escala local, quer por manutenção inadequada dos sistemas coletivos (http://www.cepis.ops-oms.org, acessado em Jul/2002).

No que tange ao problema da intermitência do fornecimento de água, calcula-se que mais de uma terça parte do abastecimento urbano na África, na América Latina e Caribe, e mais da metade na Ásia, operam em regime de intermitência. As conseqüências são limitações consideráveis na disponibilidade de água para a higiene e pressões para a aquisição de água a partir de formas alternativas menos seguras. Os outros problemas decorrentes de regimes sistemáticos de intermitência são a construção de reservatórios domiciliares para armazenamento da água, nem sempre devidamente protegidos e desinfetados; a intrusão de água contaminada nas tubulações da rede de distribuição e o próprio desgaste dessas tubulações submetidas a vazões irregulares em diferentes pressões hidráulicas (http://www.who.int/water_sanitation_health/Globalassessment / GlasspdfTOCspan.htm, acessado em Jul/2002).

No Brasil, segundo dados do Censo Demográfico de 200012 , as populações urbanas em piores condições de acesso à água representam um porcentual em torno de 10,0\%, ou seja, 17 milhões de habitantes, que só conseguem se abastecer de forma autônoma ou de forma clandestina em relação ao sistema público de abastecimento. Um outro porcentual, ligado ao sistema público, de cerca de $5,4 \%$ dos domicílios urbanos, o que corresponde a 7,5 milhões de pessoas, são domicílios sem canalização interna ainda de acordo com o Censo Demográfico de 2000 12. Isso significa que, mesmo sendo atendidos pelo sistema público, utilizam apenas uma torneira para conseguir a água que será utilizada tanto para beber e cozinhar, quanto para a limpeza da casa, a lavagem da roupa e a descarga dos vasos sanitários.

A opção de transferir a prestação de serviços para o setor privado vai acarretar a necessidade de também transferir recursos do Estado para a cobertura da não capacidade de pagamento dos custos de operação e margem de lucros, que o prestador de serviços privados requer. Mas isso ainda não é suficiente para a cobertura dos contingentes populacionais que estão fora dos sistemas públicos, ou a eles ligados de forma clandestina. 
Portanto, em sociedades de extremas desigualdades, a opção de prestar o serviço de água por meio de entes privados não coloca em primeiro plano o enfrentamento do problema do acesso universal à água potável. Isso porque, em primeiro lugar, reconhece o usuário apenas como consumidor, e não como cidadão que tem direito ao atendimento de suas necessidades básicas. Em segundo lugar, não reconhece que as condições de inacessibilidade, ou acesso precário, não são apenas operacionais, de dificuldades eventuais de pagamento, mas, sim, de graves deficiências estruturais, tanto dos sistemas de engenharia quanto do padrão urbano e das moradias.

\section{Considerações finais}

Para legitimar o seu papel protetor, o Estado também deve estender suas ações para atender às necessidades acima apontadas. Em outras palavras, o Estado deve reconhecer as situações de desigualdades de acesso e desenvolver políticas públicas para a sua resolução. O enfrentamento dos problemas de acesso à água

Resumo

Este trabalho tem por objetivo examinar o problema de saúde pública representado pelo acesso desigual à água potável, do ponto de vista das ferramentas analítica e normativa da bioética da proteção. Para tanto, por um lado, analisam-se as implicações morais do atendimento desigual de necessidades primárias, quais sejam, as situações de fragilidade e ameaça de grupos populacionais e as responsabilidades públicas para com o abastecimento de água; $e$, por outro, propõemse soluções comprometidas com a proteção da saúde pública, bem como com a promoção dos legítimos projetos de desenvolvimento pessoal. Considera-se que a aplicação da bioética da proteção permite reafirmar o papel do Estado como responsável pela prestação dos serviços de abastecimento de água, pois, ao mesmo tempo em que desaconselha as políticas de privatização não comprometidas com o bem público, justifica moralmente políticas públicas protetoras capazes de corrigir situações de injustiça social. potável envolve dois níveis de resolução. Num primeiro nível, há que ser considerado o caráter universal, de modo que seja garantido a qualquer pessoa o acesso a sistemas públicos de abastecimento de água potável. Num segundo nível, é necessário resolver, também, problemas de infra-estrutura do ambiente domiciliar, de forma a compensar as desvantagens que famílias menos favorecidas sofrem por não disporem de condições para o armazenamento e manejo adequados da água em seus domicílios. Do ponto de vista da bioética da proteção, pode-se propor, como razoável, uma solução para o problema do acesso à água potável, que atenda aos seguintes aspectos: (1) manter opção de gestão pública dos serviços de água; (2) o Estado assumir como obrigação o atendimento às necessidades básicas de acesso universal à água potável; (3) dar prioridade aos investimentos públicos para as demandas do abastecimento de água; e (4) o Estado desenvolver políticas focalizadoras para melhoria do padrão urbano e da moradia das populações em condições precárias de exclusão social, em atendimento aos requisitos da qualidade de acesso à água potável.

\section{Colaboradores}

Todos os autores participaram da montagem de um plano de trabalho onde foi definida a estrutura pela qual seriam desenvolvidos os conteúdos pertinentes. C. A. A. Pontes desenvolveu a primeira versão do artigo e realizou o tratamento final do texto. F. R. Schramm contribuiu na revisão do artigo, fazendo os devidos ajustes tanto no que diz respeito às questões referentes à teoria da bioética quanto ao exercício de análise dos problemas morais do acesso à água potável. 


\section{Referências}

1. Oliveira RM. Construindo o conhecimento sobre o saneamento básico nas favelas através das "falas" e informações da população. Cadernos CEDES 1996; 38:62-71.

2. Fernandes K. Cidade-piloto não vê fome como prioridade. Operação social - moradores de Guaribas, onde Fome Zero será lançado, consideram falta de água como questão mais grave. Folha de S. Paulo 2003 Fev 1; Caderno A. p. 8.

3. Kottow MH. Introducción a la bioética. Santiago: Editorial Universitaria; 1995.

4. Schramm FR. Bioética para quê? Revista Camiliana de Saúde 2002; 1:14-21.

5. Schramm FR, Kottow M. Princípios bioéticos en salud pública: limitaciones y propuestas. Cad Saúde Pública 2001; 17:949-56.

6. Wolf C. Theories of justice: human needs. In: Chadwick R, editor. Enciclopedia of applied ethics. v. 4. San Diego: Academic Press; 1998. p. 335-45.

7. Freitas ICC, Pessanha JEM, Heller L. A epidemiologia aplicada ao planejamento e à avaliação das ações de saneamento básico. Revista Bio 1991; jan/mar:61-6.
8. Barcellos C, Machado JH. Seleção de indicadores epidemiológicos para o saneamento. Revista Engenharia Sanitária e Ambiental 1991; 37:37-41.

9. Heller L. Associação entre cenários de saneamento e diarréia em Betim - MG: o emprego do delineamento epidemiológico caso-controle na definição de prioridade de intervenção [Tese de Doutorado]. Belo Horizonte: Escola de Veterinária, Universidade Federal de Minas Gerais; 1995.

10. Moraes LRS. Health impact of drainage and sewerage in poor urban areas in Salvador, Brazil [Tese de Doutorado]. London: London School of Hygiene and Tropical Medicine, University of London; 1996.

11. Borja PC, Moraes LRS. Sistemas de indicadores de saúde ambiental-saneamento em políticas públicas. Bahia Análise \& Dados 2001; 10:229-44.

12. Fundação Instituto Brasileiro de Geografia e Estatística. Censos Demográficos de 2000. Rio de Janeiro: Fundação Instituto Brasileiro de Geografia e Estatística; 2000.

Recebido em 14/Nov/2003

Versão final reapresentada em 30/Abr/2004 Aprovado em 10/Mai/2004 